\title{
Identification of a New Locus, Ptr(t), Required for Rice Blast Resistance Gene Pi-ta-Mediated Resistance
}

\author{
Yulin Jia and Rodger Martin \\ United States Department of Agriculture-Agriculture Research Service, Dale Bumpers National Rice Research Center, \\ Stuttgart, AR 72160, U.S.A.
}

Submitted 24 September 2007. Accepted 17 January 2008.

\begin{abstract}
Resistance to the blast pathogen Magnaporthe oryzae is proposed to be initiated by physical binding of a putative cytoplasmic receptor encoded by a nucleotide binding sitetype resistance gene, $\mathrm{Pi}$-ta, to the processed elicitor encoded by the corresponding avirulence gene $A V R$-Pita. Here, we report the identification of a new locus, $\operatorname{Ptr}(t)$, that is required for Pi-ta-mediated signal recognition. A Pi-ta-expressing susceptible mutant was identified using a genetic screen. Putative mutations at $\operatorname{Ptr}(t)$ do not alter recognition specificity to another resistance gene, $P i-k^{s}$, in the $P i$-ta homozygote, indicating that $\operatorname{Ptr}(t)$ is more likely specific to $\mathrm{Pi}$ ta-mediated signal recognition. Genetic crosses of Pi-ta $P \operatorname{Pr}(t)$ and $P$ i-ta $p t r(t)$ homozygotes suggest that $P \operatorname{tr}(t)$ segregates as a single dominant nuclear gene. A ratio of 1:1 (resistant/susceptible) of a population of BC1 of Pi-ta Ptr(t) with pi-ta $\operatorname{ptr}(t)$ homozygotes indicates that Pi-ta and $P \operatorname{tr}(t)$ are linked and cosegregate. Genotyping of mutants of pi-ta $p t r(t)$ and Pi-ta Ptr(t) homozygotes using ten simple sequence repeat markers at the $P i$-ta region determined that $P i$-ta and $P \operatorname{tr}(t)$ are located within a 9-megabase region and are of indica origin. Identification of $\operatorname{Ptr}(t)$ is a significant advancement in studying $\mathrm{Pi}$-ta-mediated signal recognition and transduction.
\end{abstract}

Additional keywords: disease resistance.

Plant resistance $(R)$ genes play important roles in preventing diseases. The molecular mechanism of $R$ gene-mediated resistance is believed to follow a gene-for-gene specificity in which an $R$ gene in plants is effective in preventing infection by pathogen races containing the corresponding pathogen avirulence genes (Flor 1971). Most $R$ genes are known to encode putative proteins with nucleotide binding sites (NBS), kinase activity, and leucine-rich repeats (LRR) that are consistent with their predicted roles as receptors in detecting the elicitors of the pathogen directly or indirectly through the products of the pathogen avirulence genes (Hulbert et al. 2001). Direct interactions of $\mathrm{R}$ proteins with avirulence proteins have been documented in four host-pathogen systems (Deslandes et al. 2003; Dodds et al. 2006; Jia et al. 2000; Scofield et al. 1996; Tang et al. 1996). In contrast, $R$ proteins were found to interact with

Current address of Rodger Martin: Oak Ridge National Laboratory, Oak Ridge, TN 37831, U.S.A.

Corresponding author: Yulin Jia; E-mail: Yulin.Jia@ars.usda.gov

This article is in the public domain and not copyrightable. It may be freely reprinted with customary crediting of the source. The American Phytopathological Society, 2008. other plant proteins modified in the presence of avirulence proteins (Axtell and Staskawicz 2003; Mackey et al. 2002, 2003).

The study of genes involved in signal transduction processes associated with disease resistance may yield new knowledge for understanding the cellular actions of $R$ genes. To date, a number of genetic methods have led to the identification of genes involved in transducing a resistance response, including yeast two-hybrid screening using cloned genes to identify interacting proteins (Zhou et al. 1997) and screening for mutants affecting the resistance phenotype, specific defense responses, or both (Innes 1998). Such screening has identified a tomato gene, $\operatorname{Prf}$, encoding a putative NBS-LRR protein (Salmeron et al. 1994, 1996). $\operatorname{Prf}$ is predicted to be involved in the Pto/AvrPto complex that transduces defense signals (Mucyn et a1. 2006). Subsequently, the Arabidopsis NDRI and EDS1 genes and the barley Rarl gene were determined to be involved in multiple $R$ gene-mediated signaling pathways (Century et al. 1997; Innes 1998; Shirasu et al.1999). Mutants with partial

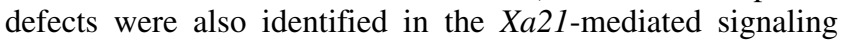
pathways (Wang et al. 2004). Thus far, mutants completely abolishing $R$ gene-mediated disease resistance, other than mutations in the $R$ gene itself, have not been reported in rice.

In the rice blast system, $40 R$ genes have been described (McCouch et al. 1994), and several, such as Pi-b, Pi-ta, Pi-d ${ }^{2}$, $P i-9$, and $P i-36$ have been molecularly characterized (Bryan et al. 2000; Chen et al. 2006; Liu et al. 2007; Qu et al. 2006; Wang et al. 1999). The Pi-b, $\mathrm{Pi}$-9, and $\mathrm{Pi}$-36 genes encode predicted NBS-LRR proteins (Qu et al. 2006; Wang et al. 1999). $P i-d^{2}$ is predicted to encode a receptor-like kinase (Chen et al. 2006). We have focused on the study of the Pi-ta gene encoding a NBS major $R$-gene type that confers resistance to $\mathrm{Mag}$ naporthe oryzae races containing the corresponding avirulence gene AVR-Pita (Bryan et al. 2000; Valent 1997). In the U.S., the tropical japonica cultivar Katy was released containing $P i$ $t a$ introgressed from the landrace indica cultivar Tetep from Vietnam (Moldenhauer et al. 1990). Historically, rice cultivars containing the resistance gene $P i$ - $t a^{2}$ exhibit a broader spectrum of resistance to pathogens than those containing Pi-ta (Rybka et al. 1997). The identification of the $P i$-ta gene in rice cultivar containing $P i-t a^{2}$ suggests that the Pi-ta gene may be needed for $P i-t a^{2}$-mediated pathogen recognition (Bryan et al. 2000; Jia et al. 2003). High resolution physical and genetic maps of $P i-t a^{2}$ near the centromere of chromosome 12 were constructed; whether or not both $P i-t a^{2}$ and Pi-ta are located at the same chromosomal location is undetermined (Nakamura et al. 1997; Rybka et al. 1997). However, among $R$ genes molecularly characterized, the Pi-ta gene is extremely valuable and is still useful in preventing blast diseases worldwide (Jia et al. 2004a; Moldenhauer et al. 1990; Wang et al. 2007). Sequence analysis of the coding regions of the Pi-ta alleles in 16 rice cultivars 
identified cultivars with one resistant $P$ i-ta haplotype and three susceptible pi-ta haplotypes (Jia et al. 2003). High conservation of DNA sequences in the Pi-ta gene led to the development of markers from $\mathrm{Pi}$-ta for marker-assisted $\mathrm{Pi}$-ta incorporation (Jia et al. 2002, 2003, 2004b).

The AVR-Pita gene determining the efficacy of Pi-ta was predicted to be a metalloprotease (Orbach et al. 2000). AVRPita is located near the telomere in some $M$. oryzae races, and was identified in archived and contemporary collections worldwide (Zhou et al. 2007). AVR-Pita encodes a putative metalloprotease, and it was shown that the product of $A V R$ Pita appears to function inside the plant cell in triggering $P i$ $t a$-mediated defense responses (Bryan et al. 2000; Jia et al. 2000). However, virulent isolates were identified with significant sequence alterations at the AVR-Pita allele, and the presence of transposon Pot 3 in the promoter region of AVR-Pita in a lab strain and in the coding region of AVR-Pita in a field strain suggests that AVR-Pita is highly unstable and is still under intensified selection (Kang et al. 2001; Zhou et al. 2007). Evidence on the product of Pi-ta binding to the product of AVR-Pita (Jia et al. 2000) led us to investigate how Pi-ta detects this highly unstable pathogen determinant (AVR-Pita) in triggering effective resistance.

In this study, we have taken a genetic approach to investigate other plant genes involved in the recognition of the $A V R$ Pita gene and transduction of defense signaling in the Pi-tamediated defense pathway. We have isolated one rice mutant from Katy altered in the ability to resist $M$. oryzae races expressing AVR-Pita. Genetic analyses indicate we have isolated mutations in a new locus, designated $P \operatorname{tr}(t)$ for $P i$-ta resistance. It was also found that $P i$-ta and $P \operatorname{tr}(t)$ cosegregated as a single locus; thus, this new information and materials provide a starting point for map-based cloning of $\operatorname{Ptr}(t)$.

\section{RESULTS}

Isolation of a rice mutant susceptible to $\mathrm{M}$. oryzae.

Among 30,000 $\mathrm{M}_{2}$ plants derived from 5,781 $\mathrm{M}_{1}$ seeds of Katy, a total of 19 susceptible Katy lines were initially identified, and their genotypes were analyzed using nine selected simple sequence repeat (SSR) markers to verify their origins
(Table 1). Five blast-susceptible mutants, M2494, M2500, M2354, M2912, and M5415, were confirmed to be from Katy. The remaining 14 susceptible lines were identified to be volunteer seeds in rice fields. These five susceptible Katy lines were further genotyped, using a panel consisting of 67 SSR markers from all 12 rice chromosomes (their chromosomal locations are listed in Table 2) to verify that they were derived from Katy. Subsequently, all five of these mutants were advanced to $\mathrm{M}_{7}$. The susceptibilities of different mutant lines to M. oryzae infection were consistently observed over multiple generations (data not shown).

\section{Analysis of the Pi-ta alleles in rice mutants.}

The $P i$-ta alleles, including $5^{\prime}$ and $3^{\prime}$ regions in five mutants, were amplified by polymerase chain reaction (PCR) (data not shown). Amplification products of the identical size as Pi-ta indicate that there were no detectable deletions in these mutants. PCR products of the expected sizes were obtained using various PCR primer pairs designed using the sequence of the Pi-ta gene (GenBank accession number AF207824) (Fig. 1). Sequence analysis of $870 \mathrm{bp}$ of $5^{\prime}$ untranslated region, the open reading frame, and the intron of the $P i$-ta gene in Figure 1 using $P i$-ta-specific primers listed in Table 3 revealed an identical Pi-ta sequence from mutant 2354 to the $P i$-ta gene. This result indicates that the putative mutations have not occurred in the Pi-ta gene in mutant 2354. However, susceptible pi-ta alleles were identified in M5415, M2500, M2494, and M2912, suggesting that these lines contain susceptible pi-ta alleles from a susceptible parent of Katy (data not shown).

Since the identical Pi-ta gene was identified in M2354, the possibility of mutations at the promoter regions was also investigated. To rule out the possibility of the promoter mutations, reverse transcription (RT)-PCR was used to amplify the region between the intron, using healthy rice leaves (Fig. 1). Similar expression of $\mathrm{Pi}$-ta in both 2354 and Katy was detected by RT-PCR (Fig. 1). Real-time RT-PCR analysis was used to determine the expression dynamics of the Pi-ta alleles in M2354 and Katy after pathogen inoculation using $P i$-ta-specific primers. As shown in Figure 2, expression of the Pi-ta allele in M2354 is similar to that in Katy at different timepoints up to $76 \mathrm{~h}$ postinoculation. These results suggest that

Table 1. Analyses of nine selected simple sequence repeats (SSR) of putative rice mutants derived from Katy

\begin{tabular}{|c|c|c|c|c|c|c|c|c|c|}
\hline \multirow[b]{2}{*}{ Mutant $^{\mathrm{a}}$} & \multicolumn{9}{|c|}{ Marker } \\
\hline & RM149 & RM190 & RM22 & RM225 & RM481 & RM231 & RM303 & RM484 & RM489 \\
\hline 1989 & 241 & 113 & 185 & 143 & 217 & 192 & NAD & 299 & 270 \\
\hline 2354 & $\mathrm{NAD}^{\mathrm{b}}$ & NAD & 192 & 143 & 217 & 181 & 144 & 293 & 270 \\
\hline 2494 & 241 & 113 & 192 & 143 & NAD & 181 & 144 & 293 & 270 \\
\hline 2500 & 241 & 113 & 192 & 143 & 217 & 181 & 144 & 293 & 270 \\
\hline 2966 & 241 & 113 & 185 & 143 & 217 & 192 & 150 & 299 & 270 \\
\hline 2912 & 241 & 113 & 192 & 143 & 217 & 181 & 144 & 293 & 270 \\
\hline 3136 & NAD & NAD & 185 & 143 & 217 & 192 & 150 & 299 & 270 \\
\hline 4395 & 241 & 113 & 192 & 143 & 217 & 181 & 144 & 293 & 270 \\
\hline 4927 & 241 & 113 & 195 & 143 & 217 & NAD & NAD & 293 & 270 \\
\hline 5171 & 241 & 113 & 185 & 143 & 217 & 192 & 150 & 299 & 270 \\
\hline 5240 & 241 & 113 & 185 & 143 & NAD & 192 & NAD & 299 & 270 \\
\hline 5322 & 241 & 113 & 192 & 143 & 217 & 181 & NAD & 299 & 270 \\
\hline 5323 & 241 & $\ldots$ & 185 & 143 & NAD & 192 & 150 & 299 & 270 \\
\hline 5326 & 241 & 113 & 185 & 143 & 217 & 192 & 150 & 299 & 270 \\
\hline 5415 & 241 & 113 & 192 & 143 & 217 & 181 & 144 & 293 & 270 \\
\hline 6868 & 241 & 113 & 185 & 143 & 217 & 192 & 150 & 299 & 270 \\
\hline 6878 & 241 & 113 & 185 & 143 & 217 & 192 & 150 & 299 & 270 \\
\hline 7025 & 241 & 113 & 185 & 143 & 217 & 192 & 150 & 299 & 270 \\
\hline 7033 & 241 & 113 & 185 & 143 & 217 & 192 & NAD & 299 & 270 \\
\hline 7040 & 241 & 113 & 185 & 143 & 217 & 192 & 150 & 299 & 270 \\
\hline Katy & 241 & 113 & 192 & 143 & 217 & NAD & 144 & 293 & 270 \\
\hline
\end{tabular}

${ }^{a}$ Bold indicates that all SSR profiles of the line are identical to the parent Katy.

${ }^{\mathrm{b}}$ NAD indicates that the datum was not of sufficient quality for analysis. 
there was no mutation in the promoter region that impacts the expression of the Pi-ta allele in 2354. Taken together, the present data are consistent with the notion that the susceptibility of M2354 is due to a mutation at a locus other than Pi-ta.

To determine the inheritance pattern of this mutation, M2354 was genetically fixed through selfing to the $\mathrm{M}_{7}$ generation and was then crossed with the parent Katy and with Tetep, the donor for Pi-ta in Katy (Table 4). In all crosses, $\mathrm{F}_{1}$ progeny were resistant. A segregation ratio of 3:1 (resistant/susceptible) was observed in $\mathrm{F}_{2}$ progeny, indicating that mutations in M2354 is controlled by a single, recessive nuclear gene, henceforth tentatively denoted as $\operatorname{ptr}(t)$.

\section{$P i$-ta and $P \operatorname{Pt}(t)$ confer resistance} to the same spectrum of $M$. oryzae.

Katy containing $P i$-ta, $P \operatorname{tr}(t)$, and $P i-k^{s}$ is historically known to be resistant to the common races of $M$. oryzae IA1, IB1, IB45, IB54, IB49, IC17, ID1, IG1, IE1, and IH1 and is susceptible to IE1k. We found that M2354 was susceptible to all the above-mentioned isolates except IB54 (Table 5). IB54 was previously shown to trigger resistance mediated by another blast resistance gene, $P i-k^{s}$. This result indicates that the defect in M2354 is related to $P i$-ta resistance but not to $P i-k^{s}$ and not to the common component downstream of defense responses. $\mathrm{Pi}$ $t a$ is effective in preventing infection by $M$. oryzae races that contain the AVR-Pita gene. We then confirmed the existence of the AVR-Pita allele, using a pair of AVR-Pita-specific PCR primers for avirulent races IB1, IB45, IB1, IB49, IB54, IC17, IG1, IE1, and IH1 and also confirmed that the AVR-Pita allele was not detected in the virulent race IE1k (data not shown). These results suggest that both Pi-ta and $P \operatorname{tr}(t)$ in Katy confer resistance to a similar spectrum of resistance to the common races of M. oryzae in the U.S..

\section{The $P \operatorname{tr}(t)$ gene cosegregates with the Pi-ta gene.}

The resistance of $F_{1}$ progeny of the cross of Katy with the susceptible cultivar M202 and the 1:1 resistant/susceptible segregation ratio (with pi-ta) among 100 individuals of backcrossing

Table 3. Oligonucleotides used for polymerase chain reaction amplification and sequencing of $P i$-ta alleles

\begin{tabular}{lll}
\hline Name & \multicolumn{1}{c}{ Position $^{\mathbf{a}}$} & \multicolumn{1}{c}{ Sequence } \\
\hline YL62 & 1510 to 1531 & 5'-GGGAGACAGCACCATCGGTGA-3' \\
YL93 & 2391 to 2371 & 5'-AAGATCAGATCAGAGCTAGT-3' \\
KG2 & 2,341 to 2,360 & 5'-ATCAGCAACTAACGAGGCAT-3' \\
F8-5 & 2,571 to 2,589 & 5'-TCCTCAGAGGCGATCTCCG-3' \\
YL68 & 3,091 to 3,110 & 5'-GGCCGACGGCGAGCCGAAGC-3' \\
YL69 & 3,310 to 3,329 & 5'-GGATGTTGGGAGGTTGATC-3' \\
YL90 & 3,751 to 3,770 & 5'-GTATGAAACATGTACTTTCA-3' \\
YL71 & 3,940 to 3,959 & 5'-AGCAGTAAGTTGTAATTTAT-3' \\
YL155 & 4,409 to 4,428 & 5'-AGCAGGTTATAAGCTAGGCC-3' \\
YL88 & 4,931 to 4,950 & 5'-TACAGGTTCAATTTCTGTTG-3' \\
YL87 & 5,431 to 5,450 & 5'-CTACCAACAAGTTCATCAAA-3' \\
YL86 & 5,699 to 5,718 & 5'-CATACACTTGACTTGTCCGA-3' \\
YL80 & 6,091 to 6,110 & 5'-CAGGATGACCTTGACACTCT-3' \\
YL82 & 6,511 to 6,530 & 5'-AGAGACTTGGATGAAGATTT-3' \\
KG4 & 6,851 to 6,870 & 5'-GACTAGGAACCACACCTTCT-3' \\
\hline
\end{tabular}

${ }^{a}$ Position based on GenBank accession number (AF207842).

Table 2. The 68 simple sequence repeat (SSR) markers assembled to verify the origin of selected Katy mutants ${ }^{\mathrm{a}}$

\begin{tabular}{|c|c|c|c|c|c|}
\hline Name & Location in Chromosome & Genetic distance & Name & Location in chromosome & Genetic distance \\
\hline RM1 & 1 & 29.7 & RM345 & 6 & 145.2 \\
\hline RM312 & 1 & 71.6 & RM481 & 7 & 3.2 \\
\hline RM5 & 1 & 94.9 & RM418 & 7 & 42.1 \\
\hline RM315 & 1 & 166.3 & RM455 & 7 & 65.7 \\
\hline RM431 & 1 & 178.3 & RM234 & 7 & 88.2 \\
\hline RM555 & 2 & 34.7 & RM420 & 7 & 115.3 \\
\hline RM452 & 2 & 58.2 & RM408 & 8 & 0 \\
\hline RM475 & 2 & 92.5 & RM25 & 8 & 52.2 \\
\hline RM106 & 2 & 123.2 & RM310 & 8 & 57 \\
\hline RM112 & 2 & 166 & RM72 & 8 & 60.9 \\
\hline RM250 & 2 & 170.1 & RM210 & 8 & 90.3 \\
\hline RM22 & 3 & 13 & RM149 & 8 & 103.7 \\
\hline RM231 & 3 & 15.7 & RM296 & 9 & 0 \\
\hline RM489 & 3 & 29.2 & RM316 & 9 & 1.8 \\
\hline RM7 & 3 & 64 & RM219 & 9 & 11.7 \\
\hline RM232 & 3 & 76.7 & RM409 & 9 & 45.6 \\
\hline RM338 & 3 & 108.4 & RM215 & 9 & 99.9 \\
\hline RM55 & 3 & 168.2 & RM474 & 10 & 0 \\
\hline RM468 & 3 & 202.3 & RM171 & 10 & 73 \\
\hline RM85 & 3 & 231 & RM228 & 10 & 96.3 \\
\hline RM307 & 4 & 0 & RM484 & 10 & 97.3 \\
\hline RM335 & 4 & 21.5 & RM147 & 10 & 99.8 \\
\hline RM471 & 4 & 53.8 & RM333 & 10 & 110.4 \\
\hline RM303 & 4 & 116.9 & RM120 & 11 & 31.7 \\
\hline RM317 & 4 & 118.3 & RM181 & 11 & 54 \\
\hline RM348 & 4 & 134.5 & RM287 & 11 & 68.6 \\
\hline RM153 & 5 & 0 & RM224 & 11 & 120.1 \\
\hline RM413 & 5 & 26.7 & RM144 & 11 & 123.2 \\
\hline RM13 & 5 & 31.4 & RM19 & 12 & 22.9 \\
\hline RM289 & 5 & 56.7 & RM512 & 12 & 43.2 \\
\hline RM164 & 5 & 78.7 & Pita $^{\mathrm{b}}$ & 12 & 60 \\
\hline RM421 & 5 & 111.2 & RM17 & 12 & 109.1 \\
\hline RM190 & 6 & 7.4 & & & \\
\hline RM225 & 6 & 26.2 & & & \\
\hline RM541 & 6 & 75.5 & & & \\
\hline RM340 & 6 & 133.5 & & & \\
\hline
\end{tabular}

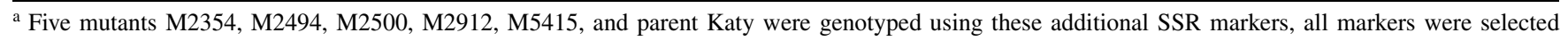
from the Gramene database.

${ }^{\mathrm{b}}$ A perfect marker for Pi-ta was used (Jia et al. 2004b). 
with M202 suggests that Pi-ta cosegregate with $P \operatorname{tr}(t)$ in the backcross progeny of Katy and M202 (data not shown). To verify the $\operatorname{Ptr}(t)$ is absent in M202, the plants of $\mathrm{F}_{1}$ progeny of the cross of M 2354 and M202 were evaluated with a race of $M$. oryzae containing AVR-Pita. The susceptibility of $\mathrm{F}_{1}$ progeny of the cross of M2354 and M202 indicates that the resistant phenotype cannot be restored by the Ptr allele in M202. Thus, we suggest that $\operatorname{Ptr}(t)$ is from Katy and it is defective in M2354.

To determine whether or not $\operatorname{ptr}(t)$ in M2354 can be complemented by $\operatorname{Ptr}(t)$ from other susceptible indica cultivars, PI 373122 (from Sri Lanka), which is known to express Pi-ta, was used for allelism tests. The likelihood was to find no fully resistant progeny, and this expectation was borne out as all 200 $\mathrm{F}_{2}$ progeny examined were susceptible (data not shown). This result suggests that the $\operatorname{Ptr}(t)$ allele in PI373122 is also nonfunctional. To determine the allelism of mutations in all blastsusceptible mutants, a series of crosses was performed among all mutants, the parent Katy, and M202 (Table 6). The susceptibility of the $F_{1}$ progeny of the crosses of M2354 with M5415, M2500, M2494, and M2912 and the crosses among all five mutants suggest that they contain allelic $\operatorname{ptr}(t)$ in the remaining mutants that confer susceptibility.

Genotyping using 10 SSR markers spanning a 10-megabase (MB) region of the Pi-ta gene and PCR-based sequence analysis using Pi-ta specific primers determined the physical location of $\operatorname{Ptr}(t)$ in these four putative mutants. As shown in Fig-
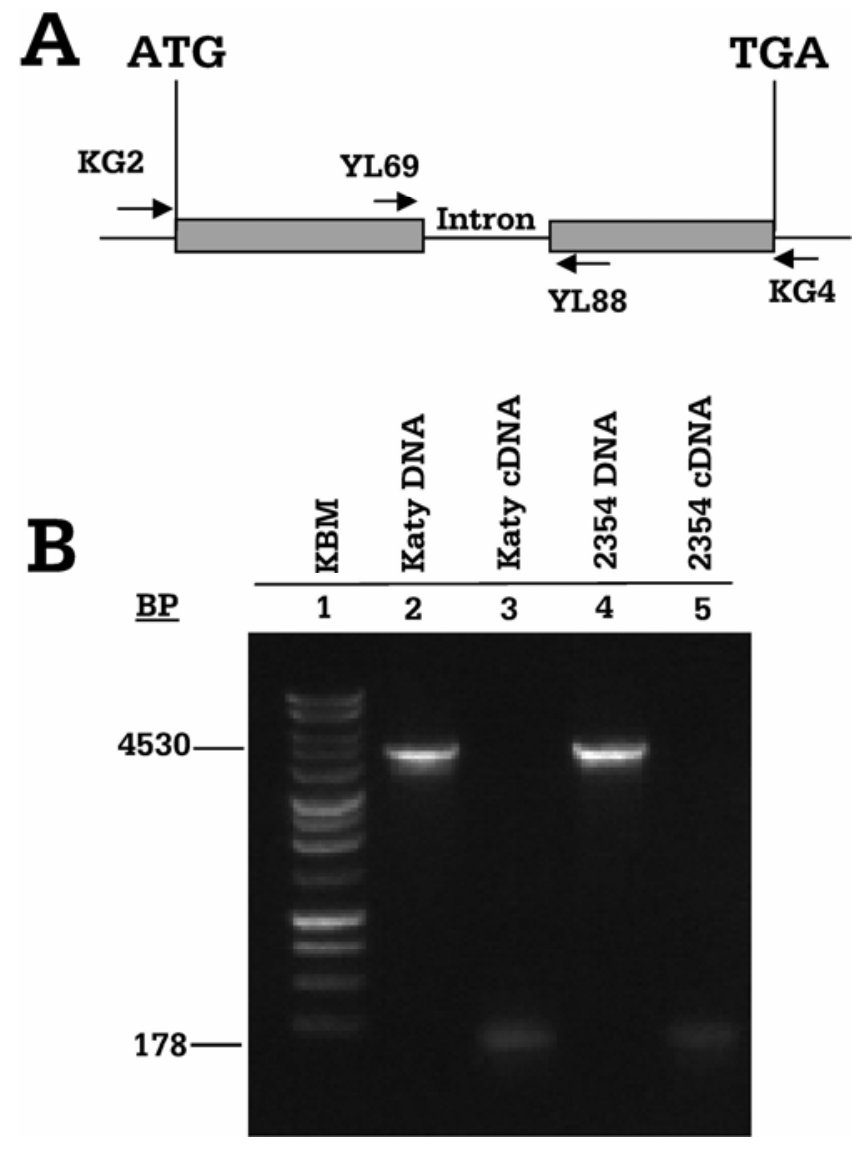

Fig. 1. Graphic presentation of the structure and expression of the Pi-ta alleles in mutant 2354 and the parent Katy, using reverse transcriptionpolymerase chain reaction (RT-PCR). A, Graphic presentation of the Pi-ta gene showing the start codon of the translation (ATG) and the stop codon (TGA). Arrows indicate the locations of indicated primers used for RTPCR and PCR. B, Gel showing the Pi-ta alleles in Katy (2) and in 2354 (4); RT-PCR product of the Pi-ta allele in Katy (3) and in 2354 (5). The Bench Top 1-kb DNA ladder (Madison, WI, U.S.A.) (1) was used to estimate the size of products of PCR and RT-PCR. ure 3, a region that is identical to a japonica parent, spanning 9 MB of the Pi-ta, Ptr(t), and centromere, was found in all mutants except M2354. These results suggest that this 9-MB region in M2354 was from Tetep and was from one of the susceptible parents in other mutants. The identical susceptible $p i$ $t a$ allele to the susceptible parent Lebonnet was identified. These data suggest that $P \operatorname{tr}(t)$ cosegregates with $P i$-ta and that both genes are located within a 9-MB region from Tetep. We conclude that a 9-MB region including susceptible pi-ta alleles in M5415, M2500, M2494, and M2912 was inherited from a susceptible parent during the breeding process.

\section{DISCUSSION}

We have identified a rice mutant harboring a defect in a critical gene controlling $P i$-ta-mediated disease resistance. DNA sequences of the coding region of $\mathrm{Pi}$-ta and its expression in a blast-susceptible mutant were determined to be identical to that of the resistant parent cultivar. Our data from sequencing and real-time PCR ruled out the possibility that mutations occurred within the Pi-ta gene. In the literature, however, most of the mutations identified in resistance pathways in plant species only partially suppress $R$ gene-mediated resistance (Innes 1998; Wang et al. 2004). For example, the barley Rarl and Rar2 genes have partial resistance phenotypes in cultivars carrying several powdery mildew $R$ genes (Shirasu et al. 1999). The partial loss of resistance suggests that genes required for disease resistance are redundant or were part of branched pathways; thus, loss of any individual gene produces only small changes in resistance. Alternatively, mutations in some signal transduction components may be lethal, since these genes are essential for plant growth and development (Innes 1998). From the present work, it is evident that resistance mediated by the resistance gene $P i-k^{s}$ is not affected by defects at the $\operatorname{Ptr}(t)$ locus. $P i$-ta gene-mediated resistance was completely abolished in a mutant harboring a defect at this new locus, $\operatorname{Ptr}(t)$, expressing the $P i$-ta gene. An additional critical nuclear gene was thus identified controlling $P i$-ta-mediated resistance.

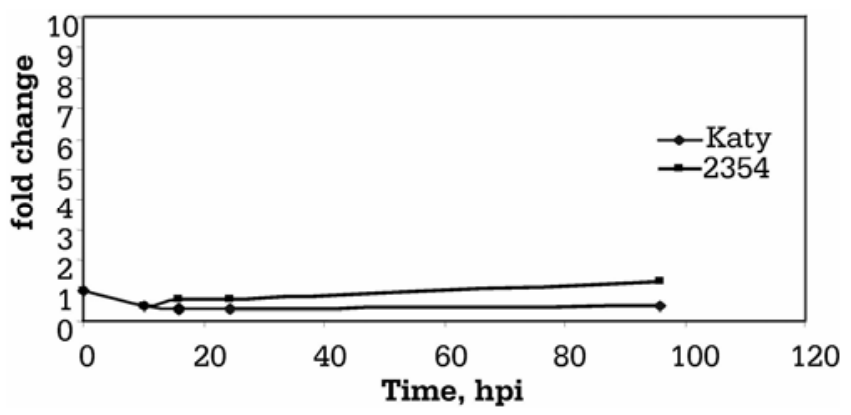

Fig. 2. Real-time polymerase chain reaction analysis of expression dynamics of the Pi-ta alleles in Katy and mutant 2354 at different timepoints after inoculation. $x$ axis = hours after inoculation of Katy and mutant with $M$. oryzae containing AVR-Pita; $y$ axis = relative expression (fold changes). Similar results were obtained in three separate trials.

Table 4. Phenotypes of segregating $F_{2}$ progeny from crosses between M2354 and resistant parents ${ }^{\mathrm{a}}$

\begin{tabular}{|c|c|c|c|c|}
\hline \multirow[b]{2}{*}{ Cross } & \multicolumn{2}{|c|}{$\mathbf{F}_{2}$} & \multirow[b]{2}{*}{$\chi^{2 b}$} & \multirow[b]{2}{*}{$P$} \\
\hline & Resistant & Susceptible & & \\
\hline 2354/Katy & 189 & 64 & 0.021 & 0.891 \\
\hline 2354/Tetep & 324 & 106 & 0.0494 & 0.760 \\
\hline
\end{tabular}

${ }^{a}$ All $F_{2}$ plants of each cross was inoculated with IB49 (ZN61) at conidial concentration of $1.5 \times 10^{6}$ conidia per milliliter in $150 \mathrm{ml}$.

${ }^{\mathrm{b}}$ A ratio of 3:1 was tested. $\chi^{2}=$ chi square and $P=$ probability. 
Although we were unable to determine the level of the Pi-ta protein in vivo, data from RT-PCR and real time RT-PCR indicated that $P i$-ta was expressed at similar levels in comparison to the original resistant parent after pathogen inoculation. Our data further support a previous observation that expression of $P i$-ta is constitutive (Bryan et al. 2000). Constitutive expression and no induction after pathogen inoculation have been observed as a common feature of blast $R$ genes molecularly characterized thus far (Bryan et al. 2000; Chen et al. 2006; Liu et al. 2007; Qu et al. 2006).

Physical binding of the Pi-ta protein to AVR-Pita during resistance responses suggests that $\mathrm{Pi}$-ta is a functional receptor for AVR-Pita (Jia et al. 2000). Differential responses to M. ory$z a e$ races could be due to another factor that distinguishes $P i$ $t a$ from $P i-t a^{2}$. In the most common races of $M$. oryzae in the U.S., highly similar AVR-Pita proteins were identified with only minor differences found among all avirulent races. However, significant structural alterations within AVR-Pita alleles have been identified in virulent and race-shift isolates, suggesting that the AVR-Pita alleles in U.S. pathotypes trigger resistance mediated by $P i-t a / P i-t a^{2}$. Using a race of $M$. oryzae specifically recognizes the $P i-t a^{2}$ gene; it was previously determined that Katy also contains $P i-t a^{2}$ (Bryan et al. 2000; Jia et al. 2003). It is known historically that $P i-t a^{2}$-containing rice cultivars exhibit a broader spectrum of resistance to different races of $M$. oryzae than those containing Pi-ta. Sequence analysis of selected $P i-t a^{2}$-containing accessions identified an

Table 6. Allelism tests of Katy mutants, their $F_{1}$ phenotypes, and the confirmation of crosses using a codominant marker for $\mathrm{Pi}$ - $\mathrm{ta}$

\begin{tabular}{lccc}
\hline Cross & No. of $\mathbf{F}_{\mathbf{1}}$ plants & Disease reaction $^{\mathbf{a}}$ & Confirmation $^{\mathbf{b}}$ \\
\hline $2354 / 2494$ & 5 & $\mathrm{~S}$ & + \\
$2354 / 2500$ & 5 & $\mathrm{~S}$ & + \\
$2354 / 5415$ & 1 & $\mathrm{~S}$ & + \\
$5415 / 2500$ & 1 & $\mathrm{~S}$ & - \\
$2912 / 2354$ & 5 & $\mathrm{~S}$ & + \\
$2912 / 2494$ & 4 & $\mathrm{~S}$ & - \\
$2912 / 2500$ & 4 & $\mathrm{~S}$ & - \\
$2912 / 5415$ & 5 & $\mathrm{~S}$ & - \\
\hline
\end{tabular}

${ }^{a}$ Disease reaction was determined using isolate ZN59 (race IC-17). R indicates resistance and $\mathrm{S}$ indicates susceptible.

${ }^{\mathrm{b}}$ A codominant marker for Pi-ta (Jia et al., 2004b) was used to confirm the true hybrids if both parents were susceptible. + indicates the true hybrids were confirmed, and - indicates the marker for Pi-ta was not useful for confirming the true hybrids due to lacking polymorphism of pi-ta.

Table 5. Disease reactions of Katy, Katy mutants, and M202 to the common Magnaporthe oryzae races

\begin{tabular}{|c|c|c|c|c|c|c|c|c|c|}
\hline \multirow[b]{2}{*}{ Name } & \multicolumn{9}{|c|}{ M. oryzae race ${ }^{\mathrm{a}}$} \\
\hline & IB1 & IB49 & IB54 $4^{\mathrm{b}}$ & IB45 & IH1 & IG1 & IC17 & IE1 & IE1K \\
\hline Katy & $\mathrm{R}$ & $\mathrm{R}$ & $\mathrm{R}$ & $\mathrm{R}$ & $\mathrm{R}$ & $\mathrm{R}$ & $\mathrm{R}$ & $\mathrm{R}$ & $\mathrm{S}$ \\
\hline FN2354 & $\mathrm{S}$ & $\mathrm{S}$ & $\mathrm{R}$ & $\mathrm{S}$ & $\mathrm{S}$ & $\mathrm{S}$ & $\mathrm{S}$ & $\mathrm{S}$ & $\mathrm{S}$ \\
\hline FN2494 & $\mathrm{S}$ & $\mathrm{S}$ & $\mathrm{R}$ & $\mathrm{S}$ & $\mathrm{S}$ & $\mathrm{S}$ & $\mathrm{S}$ & $\mathrm{S}$ & $S$ \\
\hline FN2500 & $\mathrm{S}$ & $\mathrm{S}$ & $\mathrm{R}$ & $\mathrm{S}$ & $\mathrm{S}$ & $\mathrm{S}$ & $\mathrm{S}$ & $\mathrm{S}$ & $S$ \\
\hline FN2912 & $\mathrm{S}$ & $\mathrm{S}$ & $\mathrm{R}$ & $\mathrm{S}$ & $\mathrm{S}$ & $\mathrm{S}$ & $\mathrm{S}$ & $\mathrm{S}$ & S \\
\hline FN5415 & $\mathrm{S}$ & $\mathrm{S}$ & $\mathrm{R}$ & $\mathrm{S}$ & $\mathrm{S}$ & $\mathrm{S}$ & $\mathrm{S}$ & $\mathrm{S}$ & $\mathrm{S}$ \\
\hline M202 & $\mathrm{S}$ & $\mathrm{S}$ & $\mathrm{S}$ & $\mathrm{S}$ & $\mathrm{S}$ & $\mathrm{S}$ & $\mathrm{S}$ & $\mathrm{S}$ & $\mathrm{S}$ \\
\hline
\end{tabular}

${ }^{a}$ M. oryzae races (isolates) are IB1 (ZN15), IB49 (ZN 52), IB45 (unknown), IH1(unknown), IG1 (ZN39), IC17 (ZN57), IE1 (ZN4), and IE1K (ZN19).

${ }^{\mathrm{b}}$ Race IB54 detects the presence of the $P i-k^{s}$ gene.

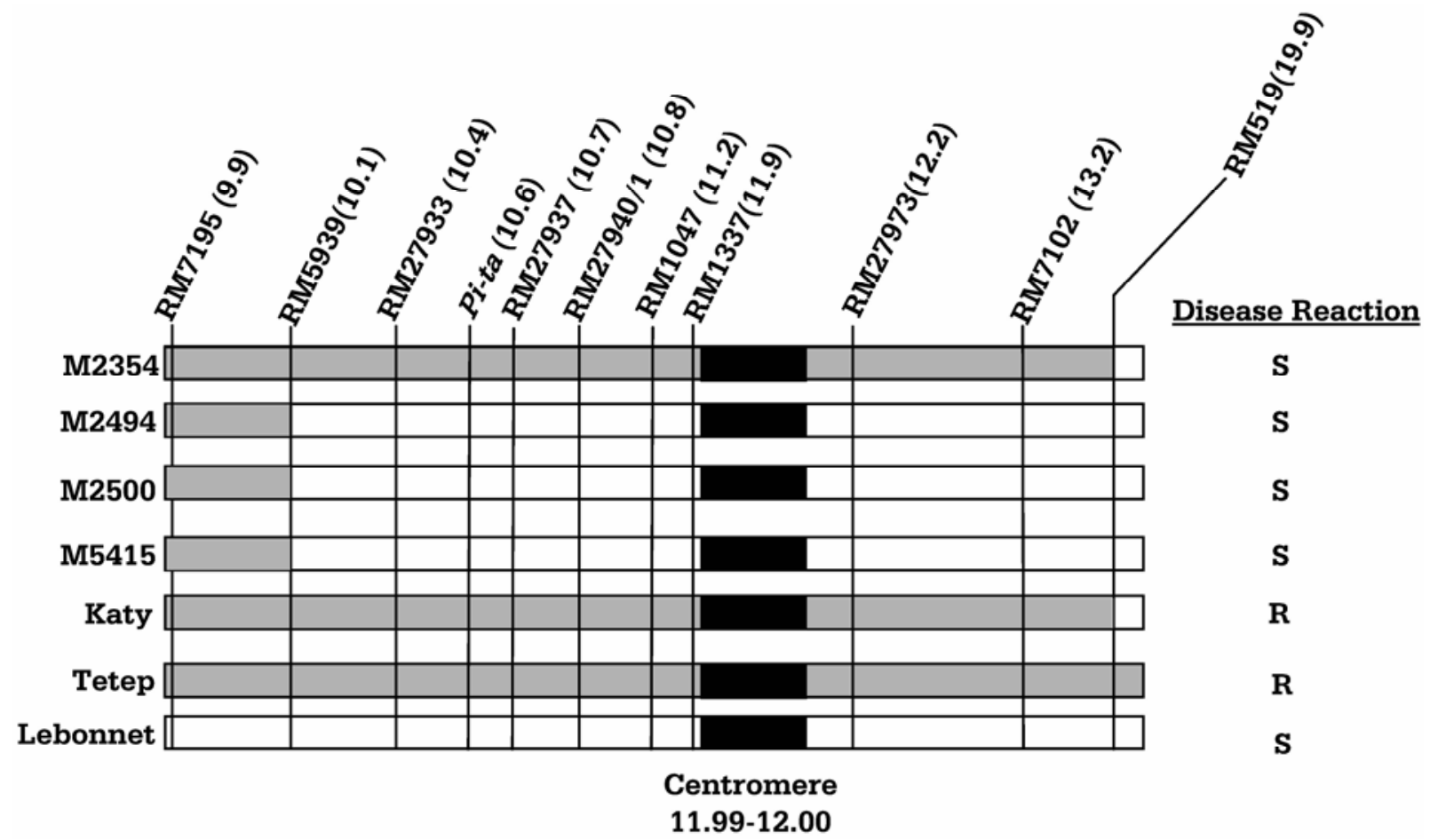

Fig. 3. Disease reactions and fine mapping of the $P i-t a / P t r(t)$ region in rice mutants and parents. $\mathrm{R}=$ resistant, $\mathrm{S}=$ susceptible. Note: Simple sequence repeat (SSR) marker RM519 was not drawn in proportion to other markers. The SSR markers were obtained from the Gramene website. 
identical resistant $P i$-ta allele, suggesting that $P i$-ta is required for the resistance function of $P i-t a^{2}$ (Jia et al. 2003). In the present study, resistance was abolished even when Pi-ta was expressed. The Pi-ta protein in Katy is identical to that of Yashiro-mochi, in which $\mathrm{Pi}$-ta was originally cloned. If Katy contains both $P i$-ta and $P i-t a^{2}$, a question arises as to whether $P t r(t)$ is $P i$-ta. If so, then the Pi-ta gene may also be $P i$ - $t a^{2}$. A more straightforward explanation for this is that $\operatorname{Ptr}(t)$ is required for both the Pi-ta and Pi-ta ${ }^{2}$ genes and $P t r(t)$ is a defect in mutant 2354. Further analysis of DNA sequences of the 9MB region spanning the Pi-ta gene in both Katy and 2354 will yield more insight into this possibility.

In our studies, we were unable to separate the $P i$-ta gene from $\operatorname{Ptr}(t)$ in a series of crosses, including the use of $2,000 \mathrm{~F}_{2}$ progeny from a segregating population derived from a cross of Pi-ta/Ptr(t) with pi-ta/ptr(t) homozygotes (Y. Jia, unpublished data). Since the Pi-ta gene is $1.39 \mathrm{MB}$ away from the centromere of chromosome 12 , it is highly possible that recombination suppression occurs at this region. Suppression of recombination around centromeres has been well documented in a wide range of eukaryotes (Anderson et al. 2003; Beadle 1932; Lambie and Roeder 1986; Mather 1993). Analysis of DNA markers located between the Pi-ta locus and the centromere will help to determine the DNA sequence of $\operatorname{Ptr}(t)$. Using SSR markers, a block within the 9-MB genomic fragment surrounding to the Pi-ta region was determined to be inherited in Katy. Genotypic analysis of a core collection (140 accessions) containing $P i$-ta revealed a $2-\mathrm{MB}$ block surrounding $P i$ - $t a$ and $\operatorname{Ptr}(t)$ that are of indica origin, thus delimiting the physical location of the $P \operatorname{tr}(t)$ gene within a 2-MB region between $P i$-ta and the centromere. Searches of publicly available databases identified a NBS-LRR candidate gene for $\operatorname{Ptr}(t)$ positioned approximately $12 \mathrm{~kb}$ from $\mathrm{Pi}$-ta (Y. Jia, unpublished data). Nevertheless, because of suppressed recombination within this region, specific markers for the $P i$-ta gene should be effective for selecting both $\mathrm{Pi}$-ta- and $\mathrm{Ptr}(\mathrm{t})$-associated resistance (Jia et al. 2002, 2004; Wang et al. 2007).

Four mutants identified in this study contain a genomic region from a susceptible parent, suggesting the cultivar is homozygous at all loci, with minor differences resulting from recombination occurring during the breeding process. This is not surprising, given that, by the time a line is established as a cultivar, it is typically in the $F_{8}$ generation or later, by which time only a small amount of residual heterozygosity exists. However, it appears from the DNA sequence and genotyping data that small genetic differences resulting from crossover events have been maintained at an extremely low frequency (four out of 5,781 individuals). Although the possibility that mutations in other regions may have occurred in these four putative mutants cannot be ruled out, a more compelling possibility is that the 9-MB genomic region was inherited from a susceptible parent.

The identification of $\operatorname{Ptr}(t)$ represents a significant advance in the understanding of $P i-t a-$ mediated disease resistance. $P i$ ta confers resistance to $M$. oryzae races expressing AVR-Pita, and $\operatorname{Ptr}(t)$ also confers resistance to these races, suggesting that either these races contain another avirulence gene or Pi-ta and $\operatorname{Ptr}(t)$ both confer resistance to the same races of $M$. oryzae expressing AVR-Pita. The presence of a $\mathrm{P} i$-ta allele of the same size and the similar expression levels of Pi-ta in mutant 2354 in comparison with the parent Katy indicate that the loss of resistance is independent of the expression of the Pi-ta gene. Further molecular and genetic analysis of Pi-ta and $\operatorname{Ptr}(t)$ should lead to a better understanding of pathogen recognition mediated by the $P i$-ta/Ptr(t) pathway and should assist in the genetic engineering of disease resistance in rice and other crop plants.

\section{MATERIALS AND METHODS}

Plant materials.

Katy containing $P i$-ta, $P i-t a^{2}$, and $P i-k^{s}$ was found to be resistant to the common $M$. oryzae U.S. races IB1 (ZN15), IB49 (ZN 52), IB 45 (unknown), IH1 (unknown), IG1 (ZN39), IE1 (ZN13), IC17 (ZN57), IE1 (ZN4), and IE1K (ZN19) (Moldenhauer et al. 1990; Y. Jia, unpublished data). Genetic analysis suggests $P i$-ta in Katy confers resistance to the major races IB49 and IC17 in the U.S. (Jia et al. 2004). M202 is susceptible to all of the above races and was used as a parent for genetic analysis (Wang et al. 2007). A susceptible indica cultivar, PI 373122, from Sri Lanka expressing Pi-ta (X. Wang and Y. Jia, unpublished data) was used for allelism tests to verify that Pi-ta cosegregates with $P \operatorname{tr}(t)$.

\section{Fast neutron mutagenesis and mutant screening.}

Our approach to studying the interaction between rice and $M$. oryzae was to isolate rice mutants that had lost resistance to $M$. oryzae. Seeds of the cultivar Katy $\left(P i-t a / P i-t a / P i-t a^{2} / P i-\right.$ $\left.t a^{2}, P i-k^{s} / P i-k^{s}\right)$ were treated with 26.3 Gy fast neutron irradiation at the Oak Ridge Laboratory (Oak Ridge, TN, U.S.A.). The $\mathrm{M}_{1}$ plants were field-grown in Stuttgart (AR, U.S.A.). A total of 5,781 $\mathrm{M}_{1}$ panicles were recovered, and $\mathrm{M}_{2}$ seed families from individual $\mathrm{M}_{1}$ plants were kept separate to facilitate screening and to ensure that mutants isolated from different $\mathbf{M}_{2}$ seed lots were independent. $\mathbf{M}_{2}$ plants were screened for disease susceptibility in the greenhouse. For blast screening, seven to ten seeds were grown in the greenhouse to three- to four-leaf stage before inoculation with a $M$. oryzae conidial suspension as described below. A total of 42 susceptible mutants were recovered from $30,000 \mathrm{M}_{2}$ seedlings, and the susceptibility was maintained in only 19 of these mutants in $\mathbf{M}_{5}$.

\section{Crossing and determination of hybrids.}

Standard methods of crossing were used for all genetic crosses. The susceptible parents were used as females for allelism tests. If $F_{1}$ progeny were resistant, the crosses were confirmed to be true crosses, because $M$. oryzae races containing $A V R$-Pita were used for inoculation. If $\mathrm{F}_{1}$ progeny were susceptible, verification of the hybrids was performed using a codominant marker for Pi-ta (Jia et al. 2004b).

\section{Fungal isolates, culture, inoculation suspension, pathogenicity assays, and identification of the AVR-Pita allele.}

$M$. oryzae races (isolates), IB1 (ZN15), IB49 (ZN 52), IB 45, IH1, IG1 (ZN39), IE1 (ZN 13), IC17 (ZN57), IE1 (ZN4), and IE1K (ZN19), were used to inoculate rice plants in this study (Correll et al. 2000). By scraping the fungal mycelia on culture plates, $M$. oryzae conidia were harvested in a sterile $0.25 \%$ gelatin solution; this conidial solution was then filtered through eight sheets of cheesecloth to remove mycelia and pieces of agar. The number of conidia per milliliter was determined by using a hemacytometer chamber. Plants were grown to the three- to four-leaf stage for inoculation and for DNA and RNA preparation. Inoculation was performed using an artist airbrush as described by Valent and associates (1991). Leaves were inoculated with layers of conidial suspensions using $10^{6}$ and $5 \times 10^{6}$ conidia per milliliter. After inoculation, the plants were placed in plastic bags and were incubated at room temperature in low light for $24 \mathrm{~h}$. Leaf-segment samples were harvested at 2, 6, 16, and $24 \mathrm{~h}$. Each leaf segment, approximately $5 \mathrm{~cm}$ in length, was detached from the marked leaf and was rapidly freeze-dried. After removing the samples, the remaining plants were removed from the plastic bags, were returned to the greenhouse, and were maintained at a temperature of 24 
to $32^{\circ} \mathrm{C}$ with a light and dark cycle of 16 and $8 \mathrm{~h}$, respectively. Disease development was monitored daily until disease symptoms were observed (5 to 7 days).

The identification of the AVR-Pita allele in races of $M$. oryzae was performed by PCR using a pair of AVR-Pita-specific primers (YL149 and YL169), using a procedure described by Zhou and associates (2007). The resulting PCR product at 1 $\mathrm{kb}$ indicates that the AVR-Pita allele is present in this race, and the absence of PCR product indicates that the AVR-Pita allele is absent in this race.

\section{SSR analysis.}

SSR analysis was used to determine the origin of susceptible mutants since $\mathrm{M}_{0}$ was grown in rice fields where volunteer seeds are common. Information about the primer sequence and map position of these SSR markers was obtained from the Gramene database. Based on high peak values, nine SSR were developed for initial screening of the genotypes of mutants, and a panel of additional markers consisting of 67 SSR and one codomimant marker for $P i$-ta were assembled for final confirmation of the genotypes of mutants. Ten more SSR spanning a $10-\mathrm{MB}$ region of the $\mathrm{Pi}$-ta gene were developed for fine mapping. DNA was prepared from fresh leaves or leaves stored at $-80^{\circ} \mathrm{C}$, using a Qiagen kit (Qiagen Sciences, Germantown, MD, U.S.A.) following the manufacturer's protocol. PCR amplification of the markers were performed in $25-\mu 1$ reaction volumes consisting of $20 \mathrm{ng}$ of genomic DNA, 10 $\mathrm{mM}$ Tris- $\mathrm{HCl}, \mathrm{pH} 8.3,50 \mathrm{mM} \mathrm{KCl}, 2.5 \mathrm{mM} \mathrm{MgCl} 2,300 \mathrm{nM}$ of each primer, 1 unit of Taq DNA polymerase (Promega, Madison, WI, U.S.A.). For each marker, forward primers labeled with fluorescent dyes (6FAM, NED, and Hex) were purchased from Applied Biosystems (Foster City, CA, U.S.A.) or Integrated DNA Technologies (Coralville, IA, U.S.A.). DNA amplifications were performed with MJ Research Tetrad thermocyclers (Waltham, MA, U.S.A.) under the following PCR conditions: i) initial denaturation at $94^{\circ} \mathrm{C}$ for $5 \mathrm{~min}$; ii) 35 cycles of $94^{\circ} \mathrm{C}$ for $1 \mathrm{~min}, 55^{\circ} \mathrm{C}$ to $67^{\circ} \mathrm{C}$ (marker dependent) for $1 \mathrm{~min}, 72^{\circ} \mathrm{C}$ for $2 \mathrm{~min}$; and iii) $5 \mathrm{~min}$ final extension at $72^{\circ} \mathrm{C}$. PCR products were pooled based on color and size range of amplified fragments (typically three markers per run along with a ROX-labeled size standard), and the DNA was denatured by heating at $94^{\circ} \mathrm{C}$ for $5 \mathrm{~min}$. The samples were run on an ABI Prism 3700 DNA analyzer according to the manufacturer's instructions (Applied Biosystems). SSR fragment sizing was performed using the software GenSan Version 3.7NT (Applied Biosystems) and Genotyper Version 3.7NT (Applied Biosystems). Alleles were binned manually.

\section{DNA sequence analysis.}

DNA sequence analysis was used to determine DNA sequences of the Pi-ta alleles in mutants. Extractions of plant genomic DNA from Katy, 2354, 2912, 2494, 5415, 2500, and M202 were prepared from leaf tissues of greenhouse-grown plants using a DNeasy plant mini kit (Qiagen Sciences, Germantown, MD, U.S.A.). Primers KG2 and KG4 (sequences and positions in the Pi-ta gene are listed in Table 3) were designed based on the Pi-ta sequence from GenBank (accession number AF207842) and were used to amplify corresponding $P i$-ta alleles. Amplification of 4,530-bp fragments was achieved using an Advantage genomic polymerase kit (Clontech, Mountain View, CA, U.S.A.). The reaction mixture for PCR consisted of $1 \times$ Advantage genomic polymerase buffer, $1.1 \mathrm{mM} \mathrm{MgCl}_{2}, 0.2 \mathrm{mM} \mathrm{dNTP}, 0.2 \mu \mathrm{M}$ primers (KG2 and KG4), $0.5 \mathrm{ng}$ of DNA template per microliter, $1 \times$ Advantage genomic polymerase mix, and PCR grade water to a final volume of $50 \mu \mathrm{l}$. Amplification was performed at $94^{\circ} \mathrm{C}$ for $1 \mathrm{~min}$, followed by 30 cycles at $94^{\circ} \mathrm{C}$ for $30 \mathrm{~s}, 53^{\circ} \mathrm{C}$ for $30 \mathrm{~s}, 70^{\circ} \mathrm{C}$ for
5 min, and 1 cycle at $70^{\circ} \mathrm{C}$ for $5 \mathrm{~min}$. Amplified fragments were cloned into the pGEM-T Easy vector (Promega) for sequencing. DNA sequencing was performed using an ABI 3700 automated DNA sequence in the genomic center at the University of Arkansas Medical Center (Little Rock, AR, U.S.A.). Primers and locations in the $\mathrm{Pi}$-ta genes for amplifying the $\mathrm{Pi}$ $t a$ fragments and sequencing the $P i$-ta alleles from mutants are listed in Table 3. DNA sequences of the Pi-ta alleles were verified by DNA sequences of PCR products of each overlapping fragment of the Pi-ta alleles in each mutant. Sequence analysis was performed using Vector NTI Advantage 10 software (Invitrogen, Carlsbad, CA, U.S.A.).

\section{RT-PCR and real time RT-PCR.}

RT-PCR was initially used to analyze the expression of the $P i$-ta allele in mutants and the parent. Total RNA was isolated from leaf tissues using an RNeasy plant mini kit (Qiagen Sciences). RT-PCR was performed to examine the expression of $P i$-ta in Katy and 2354. To avoid genomic DNA interference, the primers YL 69 and YL 88 amplify DNA sequences from each side of the intron in the Pi-ta gene. The SuperScript onestep RT-PCR with platinum Taq kit (Invitrogen) was used with primers YL69 and YL88 (Table 3) to generate a 178-bp product from the coding region. Reactions (total volume of $50 \mu \mathrm{l}$ ) included: $1 \times$ reaction buffer, $0.2 \mathrm{mM} \mathrm{dNTP}, 0.2 \mu \mathrm{M}$ primers, $2.5 \mathrm{ng}$ of total RNA per microliter, $1 \mu \mathrm{l}$ RT/platinum Taq mix, and $21 \mu \mathrm{l}$ of PCR-grade water. RT-PCR was performed with a thermal cycler using 1 cycle at $45^{\circ} \mathrm{C}$ for $30 \mathrm{~min}, 1$ cycle at $94^{\circ} \mathrm{C}$ for $2 \mathrm{~min}$, followed by 35 cycles at $94^{\circ} \mathrm{C}$ for $15 \mathrm{~s}, 52^{\circ} \mathrm{C}$ for $30 \mathrm{~s}, 68^{\circ} \mathrm{C}$ for $1 \mathrm{~min}$ with a final extension at $72^{\circ} \mathrm{C}$ for 5 min. The resulting products were subjected to electrophoresis using a $1 \%$ agarose gel and were photographed using a ChemiDoc imaging system (BioRad, Hercules, CA, U.S.A.). All results were repeated in three independent trials.

Real time RT-PCR analysis was used to determine the expression dynamics of $\mathrm{Pi}$-ta in Katy and mutant 2354 at different timepoints after infection. New primers $\left(5^{\prime}\right.$-ATCGACTCC TTGAAACTATCC-3' and 5'-AGTATTCTACTGCAACTATTA TTATC-3') and hydrolysis probes were designed from opposite exons of Pi-ta (GenBank accession number AF 207842). Total RNA was prepared from leaf tissues of infected rice plants at the four-leaf stage at $6,10,16,24$, and $48 \mathrm{~h}$ postinoculation, using an RNeasy plant mini kit (Qiagen Sciences). Real-time PCR was performed, using an iScript one-step RTPCR kit for probes (Bio-Rad) according to the manufacturer's instructions. Reaction conditions were $50^{\circ} \mathrm{C}$ for $10 \mathrm{~min}, 95^{\circ} \mathrm{C}$ for $5 \mathrm{~min}, 95^{\circ} \mathrm{C}$ for $10 \mathrm{~s}, 51^{\circ} \mathrm{C}$ for $30 \mathrm{~s}$. Relative quantification of gene expression was performed using the comparative cycle threshold method. 18S ribosomal RNA was used as an internal control. All results were repeated in three independent trials.

\section{ACKNOWLEDGMENTS}

We thank the University of Arkansas Rice Research Promotion Board for providing support to $\mathrm{L}$. Wu, S. Pinson for introduction of our collaborator R. Martin at the Californium User Facility for Neutron Science at Oak Ridge National Laboratory, M. Lin for evaluation of disease reactions and crossing, K. Gubrij for sequencing the Pi-ta alleles and expression analysis of the Pi-ta alleles, M. H. Jia for SSR genotyping analysis and proof reading, T. Beaty for all field operations, L. Wu, R. Clemons, and K. Pratt for their excellent technical support. We thank K. Moldenhauer for providing Katy rice and discussions on the development of Katy cultivar and W. Yan for providing other rice germplasm used in this study.

\section{LITERATURE CITED}

Anderson, L. K., Doyle, G. G., Brigham, B., Carter, B., Hooker, K. D., Lai, A., Rice, M., and Stack, S. M. 2003. High resolution crossover 
maps for each bivalent of Zea mays using recombination nodules. Genetics 165:849-865.

Axtell, M. J., and Staskawics, B. J. 2003. Initiation of RPS2-specified disease resistance in Arabidopsis is coupled to the AvrRPt2-directed elimination of RIN4. Cell 112:369-377.

Beadle, G. W. 1932. A possible influence of the spindle fibre on crossingover in Drosophila. Proc. Natl. Acad. Sci. U.S.A. 18:160-165.

Bryan, B. T., Wu, K. S., Farrall, L., Jia, Y., Hershey, H., McAdams, S., Tarchini, R., Donaldson, G., Faulk, K., and Valent, B. 2000. A single amino acid difference distinguishes resistant and susceptible allele of the rice blast resistance gene Pi-ta. Plant Cell 12:2033-2045.

Century, K. S., Shapiro, A. D., Repetti, P. P., Dahlbeck, D., Holub, E., and Staskawicz, B. J. 1997. NDRI, a pathogen-induced component required for Arabidopsis disease resistance. Science 278:1963-1965.

Chen, X., Shang, J., Chen, D. Lei, C., Zou, Y., Zhai, W., Liu, G., Xu, J., Ling, Z., Cao, G., Ma, B., Y. Wang, X. Zhao, Li, S., and Zhu, L. 2006. A $\mathrm{B}$-lectin receptor kinase gene conferring rice blast resistance. Plant J. 46:794-804.

Correll, J. C., Harp, T. L., Guerber, J. C., Zeigler, R. S., Liu, B., Cartwright, R. D., and Lee, F. N. 2000. Characterization of Pyricularia grisea in the United States using independent genetic and molecular markers. Phytopathology 90:1396-1404.

Deslandes, L., Oliver, J., Peters, N., Feng, D. X., Khounlotham, M., Boucher, C., Somssich, I., Genin, S., and Marco, Y. 2003. Physical interaction between $R R S 1-R$, a protein conferring resistance to bacterial wilt, and $P o p P 2$, a type III effector targeted to the plant nucleus. Proc. Natl. Acad. Sci. U.S.A. 100:8024-8029.

Dodds, P., Lawrence, G. J., Catanzariti, A.-M., Teh, T., Wang, C.-I. A., Ayliffe, M. A., Kobe, B., and Ellis, J. G. 2006. Direct protein interaction underlines gene-for-gene specificity and coevolution of the flax resistance genes and flax rust avirulence genes. Proc. Natl. Acad. Sci. U.S.A. 103:8888-8893.

Flor, H. H. 1971. Current status of the gene-for-gene concept. Annu. Rev. Phytopathol. 9:275-296.

Hulbert, S. H., Webb, C. A., Smith, S. M., and Sun, Q. 2001. Resistance gene complexes: Evolution and utilization. Annu. Rev. Phytopathol. 39:285-312.

Innes, R. W. 1998. Genetic dissection of $R$ gene signal transduction pathways. Curr. Opin. Plant Biol. 1:229-304.

Jia, Y., McAdams, S. A., Bryan, G. T., Hershey, H. P., and Valent, B. 2000 Direct interaction of resistance gene and avirulence gene products confers rice blast resistance. EMBO (Eur. Mol. Biol. Org.) J. 19:40044014

Jia, Y., Wang, Z., and Singh, P. 2002. Development of dominant rice blast resistance $P i$-ta gene markers. Crop Sci. 42:2145-2149.

Jia, Y., Bryan, G. T., Farrall, L., and Valent, B. 2003. Natural variation at the Pi-ta rice blast resistance locus. Phytopathology 93:1452-1459.

Jia, Y., Wang, Z., Fjellstrom, R. G., Moldenhauer, K. A. K., Azam, M. A., Correll, J., Lee, F. N., Xia, Y., and Rutger, J. N. 2004a. Rice Pi-ta gene confers resistance to the major pathotypes of the rice blast fungus in the US. Phytopathology 94:296-301.

Jia, Y., Redus, M., Wang, Z., and Rutger, J. N. 2004b. Development of a SNLP marker from the Pi-ta blast resistance gene by tri-Primer PCR. Euphytica 138:97-105.

Kang, S., Lebrun, M. H., Farrall, L., and Valent, B. 2001. Gain of virulence caused by insertion of a Pot 3 transposon in a Magnaporthe grisea avirulence gene. Mol. Plant-Microbe Interact. 14:671-674.

Lambie, E. J., and Roeder, G. S. 1986. Repression of meiotic crossing over by a centromere (CEN3) in Saccharomyces cerevisiae. Genetics 114:769-789.

Liu, X., Lin, F., Wang, L., and Pan, Q. 2007. The in silico map based cloning of Pi36, a rice coiled-coil-nucleotide binding site leucine rich repeat gene that confers race specific resistance to the blast fungus. Genetics 176:2541-2549.

Mackey, B. Holt, Wing A., and Dangl, J. 2002. RIN4 interacts with Pseudomonas syringae type III effector molecules and is required for RPM1-mediated resistance in Arabidopsis. Cell 108:743-754.

Mackey, D., Belkhadir, Y., Alonzo, J. M., Ecker, J. R., and Dangl, J. L. 2003. Arabidopsis RIN4 is a target of the type III virulence effector AvrRpt 2 and modulates RPS-mediated resistance. Cell 112:379-389.

Mather, K. 1993. Crossing over and heterochromatin in the X chromosome of Drosophila melanogaster. Genetics 24:413-435.

McCouch, S. R., Nelson, R. J., Tome, J., and Zeigler, R. S. 1994. Mapping of blast resistance genes in rice. Pages 167-186 in: Rice Blast Disease.
R. S. Zeigler, S. A. Leong, and P. S. Teng, eds. CAB International Wallingford, U.K.

Moldenhauer, K. A. K., Lee, F. N., Norman, R. J., Helms, R. S., Well, R. H., Dilday, R. H., Rohman, P. C., and Marchetti, M. A. 1990. Registration of 'Katy' rice, Crop Sci. 30:747-748.

Mucyn, T. S., Clemente, A., Andriotis, W. M. E., Balamuth, A. 1., Oldroyd, G. E. D, Staskawics, B. J., and Rathke, J. P. 2006. The tomato NRARCLRR protein Prf interacts with Pto kinase in vivo to regulate specific plant immunity. Plant Cell 18:2792-2806.

Nakamura, S., Asakawa, S., Ohmido, N., Fukui, K., Shimizu, N., and Kawasaki, S. 1997. Construction of an 800-kb contig in the near-centromeric region of the rice blast resistance gene $P i-t a^{2}$ using a highly representative rice BAC library. Mol. Gen. Genet. 254:611-620.

Orbach, M. J., Farrall, L., Sweigard, J., Chumley, F. G., and Valent B. 2000. A telomeric avirulence gene determines efficacy for the rice blast resistance gene $P i$-ta, Plant Cell 12:2019-2032.

Qu, S., G. Liu, Zhou, B., Pellizzi, M., Zeng, L., Dai, L., Han, B., and Wang G.-L. 2006. The broad-spectrum blast resistance gene Pi9 encodes a nucleotide-binding site-leucine-rich repeat protein and is a member of multigene family in rice. Genetics 172:1901-1914.

Rybka, K., Miyamoto, M., Ando, I., Saito, A., and Kawasaki, S. 1997. High resolution mapping of the indica-derived rice blast resistance genes. II. Pi-ta ${ }^{2}$ and Pi-ta and a consideration of their origin. Mol. Plant-Microbe Interact. 10:517-524.

Salmeron, J. M., Barker, S. J., Garland, F. M., Mehta, A. Y., and Staskawicz, B. J. 1994. Tomato mutants altered in bacterial disease resistance provide evidence for a new locus controlling pathogen recognition. Plant Cell 6:511-520.

Salmeron, J. M, Oldroyd, G. E. D., Rommens, C. M. T., Scofield, S. R., Kim, H. S., Labelle, D. T., Rahbeck, D., and Staskawicz, B. J. 1996. Tomato Prf is a member of the leucine-rich repeats class of disease resistance genes and lies embedded within the Pto kinase gene cluster. Cell 86:123-133.

Scofield, S. R., Tobias, C. M., Rathjen, J. P., Chang, J. H., Labelle, D. T., Michelmore, R. W., and Staskwicz, B. J. 1996. Molecular basis of genefor-gene specificity in bacterial speck disease of tomato. Science 268:661-667.

Shirasu, K., Ahaee, T., Tan, M. W., Zhou, F., Azevedo, C., and SchulzeLefert, P. 1999. A novel class of eukaryotic zinc-binding proteins is required for disease resistance signaling in barely and development in C. elegans. Cell 12:355-366.

Tang, X., Frederick, R. D., Zhou, J., Halterman, D. A., Jia, Y., and Martin, G. B. 1996. Initiation of plant disease resistance by physical interaction of AvrPto and Pto kinase. Science 274:2060-2063.

Valent, B. 1997. The Rice Blast Fungus, Magnaporthe grisea. Plant Relationships. Pages 37-54 in: The Mycota V Part B. G. C. Carroll and P. Tudzynoski, eds. Springer-Verlag, Berlin, Germany.

Valent, B., Farrall, L., and Chumley, F. G. 1991. Magnaporthe grisea genes for pathogenicity and virulence identified through a series of backcrosses. Genetics 127:87-101.

Wang, G. L., Wu. C.,'Zeng, L.,'He, C., Baraoidan, M., de Assis Goes da Silva, F.,Williams, C. E., Ronald, P. C., and Leung, H. 2004. Isolation and characterization of rice mutants compromised in $\mathrm{Xa21}$-mediated resistance to X. oryzae pv. Oryzae. Theor Appl Genet. 108:379-384.

Wang, Z., Jia, Y., Rutger, J. N., and Xia, Y. 2007. Rapid survey for presence of a blast resistance gene $P i$-ta in rice cultivars using the dominant DNA markers derived from portions of the Pi-ta gene. Plant Breed. 126:36-42.

Wang, Z.-X., Yano, M., Yamanouchi, U., Iwamoto, M., Mona, L., Hayasaka, H., Katayose, Y., and Sasaki, T. 1999. The Pib gene for rice blast resistance belongs to the nucleotide binding and leucine-rich repeat class of plant disease resistance genes. Plant J. 19:55-64.

Zhou, J., Tang, X., and Martin, G. B. 1997. The Pto kinase conferring resistance to tomato bacterial speck disease interacts with proteins that bind a cis-element of pathogenesis related genes. The (Euro. Mol. Biol. Org.) EMBO (Eur. Mol. Biol. Org.) J. 16:3207-3218.

Zhou, E., Jia, Y., Singh, P., Correll, J. C., and Lee, F. N. 2007. Instability of the Magnaporthe Oryzae avirulence gene AVR-Pita alters virulence. Fungal Genet. Biol. 44:1024-1034.

\section{AUTHOR-RECOMMENDED INTERNET RESOURCE}

The Gramene database: www.gramene.org 